\title{
EXCLUSIVE POTASSIUM DEPENDENCE OF THE MEMBRANE POTENTIAL IN CULTURED MOUSE OLIGODENDROCYTES ${ }^{1}$
}

\author{
H. KETTENMANN, U. SONNHOF, AND M. SCHACHNER ${ }^{2}$ \\ Department of Neurobiology, University of Heidelberg, Im Neuenheimer Feld 504, D-6900 \\ Heidelberg, Federal Republic of Germany
}

Received June 21, 1982; Revised September 8, 1982; Accepted September 9, 1982

\begin{abstract}
Membrane potential, conductance, and intracellular potassium concentration were measured in oligodendrocytes in 3- to 10-week-old cultures of embryonic mouse spinal cord. After intracellular recording the cells were first injected with Lucifer Yellow and then stained by immunofluorescence using rhodamine-labeled monoclonal antibody 01 specific for oligodendrocyte cell surfaces. The membrane potential of these identified oligodendrocytes was in $\mathrm{mV}-66 \pm 4.3 \mathrm{SD}$; it could be reversibly reduced almost to zero by the addition of ouabain. Changes in external $\mathrm{K}^{+}$but not $\mathrm{Na}^{+}$, $\mathrm{Ca}^{++}$, or $\mathrm{Cl}^{-}$changed the membrane potential. A 10 -fold increase in extracellular potassium concentration $\left(\left[\mathrm{K}^{+}\right]_{0}\right)$ depolarized the cell by about $52 \mathrm{mV}$. This is less than the $61 \mathrm{mV}$ predicted by the Nernst equation for a $\mathrm{K}^{+}$electrode assuming a constant intracellular potassium concentration $\left(\left[\mathrm{K}^{+}\right]_{\mathrm{i}}\right)$. However, when $\left[\mathrm{K}^{+}\right]_{\mathrm{i}}$ was measured with an ion-selective electrode during the increase in $\left[\mathrm{K}^{+}\right]_{0}$ it was found to rise. The Nernst equation for $\mathrm{K}^{+}$accurately predicts the oligodendrocyte membrane potential when the increase in $\left[\mathrm{K}^{+}\right]_{\mathrm{i}}$ is taken into account. Oligodendrocytes may be described as accurate $\mathrm{K}^{+}$electrodes with a variable reference solution.
\end{abstract}

The membrane potential $\left(V_{m}\right)$ of glial cells depends on the extracellular potassium activity. In the optic nerve of Necturus the glial cell membrane behaves as an accurate electrode for $\left[\mathrm{K}^{+}\right]$from about 2 to $200 \mathrm{mmol} / \mathrm{liter}$. This means that the membrane potential can be described by the Nernst equation $\left(V_{m}=R \cdot T / Z \cdot F \ln \left[\mathrm{K}^{+}\right]_{0} /\left[\mathrm{K}^{+}\right]_{i}\right)$ for extracellular potassium changes assuming a constant intracellular potassium concentration (Kuffler et al., 1966). In the mammalian central nervous system, some authors have found good agreement between the glial $V_{m}$ and the Nernst prediction (Lothman and Somjen, 1975), whereas others have found a considerable discrepancy from the predicted values (Ransom and Goldring, 1973; Futamachi and Pedley, 1976; for reviews see Orkand, 1977 and Somjen, 1975, 1979). Several hypotheses have been proposed to explain the discrepancy between the observed $V_{m}$ and that predicted for a $\mathrm{K}^{+}$electrode. These include possible diffusion barriers, a significant membrane con-

\footnotetext{
${ }^{1}$ We are indebted to R. K. Orkand for stimulating discussions and comments on the manuscript, I. Sommer for help with the antibodies, and W. Stewart for supplying Lucifer Yellow. The technical assistance of Mrs. G. Scheib and Mrs. A. Kühner is gratefully acknowledged. We thank Mrs. M. Shrady for typewriting the manuscript. This work was supported by Deutsche Forschungsgemeinschaft (Scha 185/6) and Studienstiftung des deutschen Volkes.

${ }^{2}$ To whom correspondence should be addressed.
}

ductance to other ions, electrogenic pumps, leakage currents, and changes in $\left[\mathrm{K}^{+}\right]_{\mathrm{i}}$ (Picker et al., 1981). Most of the above cited recordings were presumably made from astrocytes. There is little known of the electrical properties of oligodendrocytes or of their $V_{m}$ and its ionic basis.

In a culture system, Moonen and Nelson (1978) studied the electrophysiological properties of avian astrocytes. Their cultures contained about $10 \%$ of nonglial cells, and positive identification of individual cells was, therefore, not possible. In the present study our culture system also contained more than one cell type. However, following recording of electrical properties or intracellular potassium, the cell was injected with Lucifer Yellow (Stewart, 1981) and then the entire culture was incubated with the monoclonal antibody 01 which selectively stains the more mature oligodendrocytes (Sommer and Schachner, 1981; Schachner et al., 1981). This permitted positive identification of the cell which was studied.

\section{Materials and Methods}

Cell culture. Explant cultures of spinal cord were obtained from embryos of NMRI or C57BL/6J mice. The day a vaginal plug was found was designated as embryonic day 1 . On day 14 , under sterile conditions, the spinal cord was dissected out, cut into transverse slices about 1 $\mathrm{mm}$ thick, and placed on glass coverslips coated with dry 
collagen (Sigma, Munich, FRG). The explants were maintained without antibiotics in Eagle's Basal Medium with Earle's salts supplemented with $10 \%$ calf serum (Seromed, Munich, FRG) at $35.5^{\circ} \mathrm{C}$ in a humidified $3.5 \%$ $\mathrm{CO}_{2}$-air atmosphere. Cultures were fed weekly by replacing approximately half of the culture medium and were studied 3 to 10 weeks after dissection.

Electrophysiological measurements. Single barreled electrodes pulled from glass capillaries with filaments (Clark Electromedical Instruments, Pangbourne, England) and filled with $3 \mathrm{~mol} / \mathrm{liter}$ of potassium acetate were used for current injection. Double barreled $\theta$ glass capillaries were used for dye injection and registration of membrane potential. One barrel was filled with $3 \mathrm{~mol} /$ liter of potassium acetate and the other with $4 \%$ Lucifer Yellow in distilled water. Measurements of ion concentrations and potential were performed with the same type of $\theta$ electrodes with unbroken tips in which the barrel for potential recording was filled with $200 \mathrm{mmol} /$ litcr of $\mathrm{NaCl}$ for $\mathrm{K}^{+}$and $\mathrm{Ca}^{++}$and with $200 \mathrm{mmol} /$ liter of $\mathrm{K}^{+}$-acetate for $\mathrm{Cl}^{-}$measurements. The barrel for ion measurement, after silanization with trimethyl chlorosilane, was filled from behind with an exchange resin (for $\mathrm{K}^{+}$and choline: Corning 477317 ; for $\mathrm{Ca}^{++}$: neutral carrier from Prof. Simon, Zürich; for $\mathrm{Cl}^{-}$: Orion exchange resin). As back-filling solutions, $200 \mathrm{mmol} /$ liter of $\mathrm{KCl}$ for $\mathrm{K}^{+}$ and $\mathrm{Cl}^{-}$and $120 \mathrm{mmol} /$ liter of $\mathrm{CaCl}_{2}$ for $\mathrm{Ca}^{++}$-sensitive electrodes were used (for detailed description and discussion see Sonnhof and Bührle, 1980). In some cases cells were stained with Lucifer Yellow by using 4\% Lucifer Yellow in the potential registration barrel. Staining was accomplished by applying constant current of about $5 \mathrm{nA}$ for 2 to $4 \mathrm{~min}$.

The culture dish was mounted on the stage of a Zeiss inverted microscope and maintained in a recording chamher at $35.5^{\circ} \mathrm{C}$ in a $3.5 \% \mathrm{CO}_{2}$ atmosphere. For electrophysiological measurements, the culture medium was replaced by a solution of salts containing in mmol/liter $116.4 \mathrm{NaCl}, 5.4 \mathrm{KCl}, 1 \mathrm{NaH}_{2} \mathrm{PO}_{4} \cdot \mathrm{H}_{2} \mathrm{O}, 0.8 \mathrm{MgSO}_{4} \cdot 7 \mathrm{H}_{2} \mathrm{O}$, $1.7 \mathrm{CaCl}_{2}, 5.6$ D-glucose, 26.2 $\mathrm{NaHCO}_{3}$. To increase $\left[\mathrm{K}^{+}\right]_{0}$, the dish was perfused with a modified solution in which equimolar amounts of $\mathrm{NaCl}$ were replaced by $\mathrm{KCl}$. For measurements of membrane potential at low extracellular $\mathrm{Na}^{+}, \mathrm{NaCl}$ was replaced by choline chloride; for low $\mathrm{Cl}^{-}, \mathrm{NaCl}$ was replaced by $\mathrm{Na}^{+}$-methylsulfate.

Cells were penetrated with the aid of a step-motor driven manipulator (Sonnhof et al., 1982) using a step size of $1.9 \mu \mathrm{m}$ and a step velocity of $5 \mathrm{~mm} / \mathrm{sec}$. Conventional amplifiers were used for recordings of potential and ion activities. Signals were registered on a pen writer, an FM tape, a storage oscilloscope, and an X-Y plotter. The reference electrode was an $\mathrm{Ag}$-AgCl pellet connected to the bathing fluid via a strip of filter paper.

Immunocytological procedures. After recording and dye injection, cultures were labeled with monoclonal antibody 01 to specifically mark the cell surfaces of the more differentiated oligodendrocytes (Sommer and Schachner, 1981, 1982; Schachner et al., 1981). Indirect immunofluorescence was carried out on live cells as described previously (Sommer and Schachner, 1981; Schnitzer and Schachner, 1981) using tetramethylrhodamine as the fluorochrome to distinguish it from Lucifer Yellow fluorescence. In brief, live unfixed cells on cover- slips were incubated for $15 \mathrm{~min}$ at room temperature with the antibody 01 diluted 1:20 or 1:50 in culture medium. Coverslips were washed twice in culture medium, incubated with a freshly prepared solution of $4 \%$ paraformaldehyde in phosphate-buffered saline, $\mathrm{pH} 7.3$, and washed again twice in culture medium, all at room temperature. Cells were then incubated with goat anti-mouse immunoglobulin antibodies coupled with tetramethylrhodamine (GAR-TRITC; from Dynatech, Plochingen, FRG) diluted 1:100 in culture medium. After $15 \mathrm{~min}$ at room temperature, coverslips were washed again twice, mounted in glycerol-phosphate-buffered saline, $\mathrm{pH} \mathrm{7.3,}$ placed upside down on a slide, and inspected with a Zeiss fluorescence microscope with phase optics and the appropriate filters for detection of Lucifer Yellow (BP 450-490, FT 510, and LP 520) and tetramethylrhodamine (BP 545, FT 580, and LP 590).

\section{Results}

Immunocytochemical identification of oligodendro cytes after electrophysiological measurement and Lucifer Yellow injection. To identify individual cells after intracellular recording, cells were injected with Lucifer Yellow and stained by indirect immunofluorescence with the monoclonal antibody 01. The intracellular greenishyellow fluorescence of Lucifer Yellow and oligodendrocyte-specific cell surface labeling with the red fluorochrome tetramethylrhodamine allow an unequivocal identification of the cell (Fig. 1). The spectra of the two fluorescent dyes could be separated completely by use of appropriate filters. Labeled structures were correlated with the appearance of cells in phase contrast optics.

Resting membrane potential. The mean value of resting membrane potential of oligodendrocytes was in $\mathrm{mV}$ $-66 \pm 4.3 \mathrm{SD}(N=40)$. After penetration the membrane potential reached a stable value within $5 \mathrm{~min}$ and often fluctuated less than $5 \mathrm{mV}$ for periods up to a few hours. Cells which did not give stable values of at least $-60 \mathrm{mV}$ within $10 \mathrm{~min}$ after penetration were not used.

Effect of ouabain on the membrane potential. As shown in Figure 2, the addition of $10^{-4} \mathrm{~mol} / \mathrm{liter}$ of ouabain to the bath depolarized the cell near to zero in 10 to $20 \mathrm{~min}$. Ten cells were tested, which all showed a similar behavior. The effect could be reversed by replacement of ouabain with ouabain-free bathing solution.

Intracellular potassium activity. Stable intracellular recordings with $\mathrm{K}^{+}$-sensitive electrodes were less frequent than with electrolyte-filled electrodes. Figure 1 shows a recording of potential and potassium concentration $\left[\mathrm{K}^{+}\right]$during penetration. Average $\left[\mathrm{K}^{+}\right]_{\mathrm{i}}$ was 74.3 $\mathrm{mol} / \mathrm{liter} \pm 16 \mathrm{SD}(\mathrm{N}=14)$. The corresponding calculated potassium equilibrium potential was $-69.7 \mathrm{mV}$ $(+5.2$ and $-6.4 \mathrm{SD})$.

Membrane potential and variations of extracellular $\mathrm{Na}^{+}, \mathrm{Ca}^{++}$, and $\mathrm{Cl}^{-}$. The ionic composition of the medium bathing an oligodendrocyte was changed while continuously recording the membrane potential. When $\mathrm{Na}^{+}$ions were replaced by choline (Fig. $3 B$ ) or $\mathrm{Cl}^{-}$by methylsulfate (Fig. $3 D$ ), no effect on the membrane potential of 10 investigated cells was observed. A decrease of $\mathrm{Ca}^{++}$from 1.7 to $0.01 \mathrm{mmol} /$ liter also did not affect the membrane potential of seven tested cells (Fig. $3 C$ ). Solutions were varied by exchange of the superfu- 

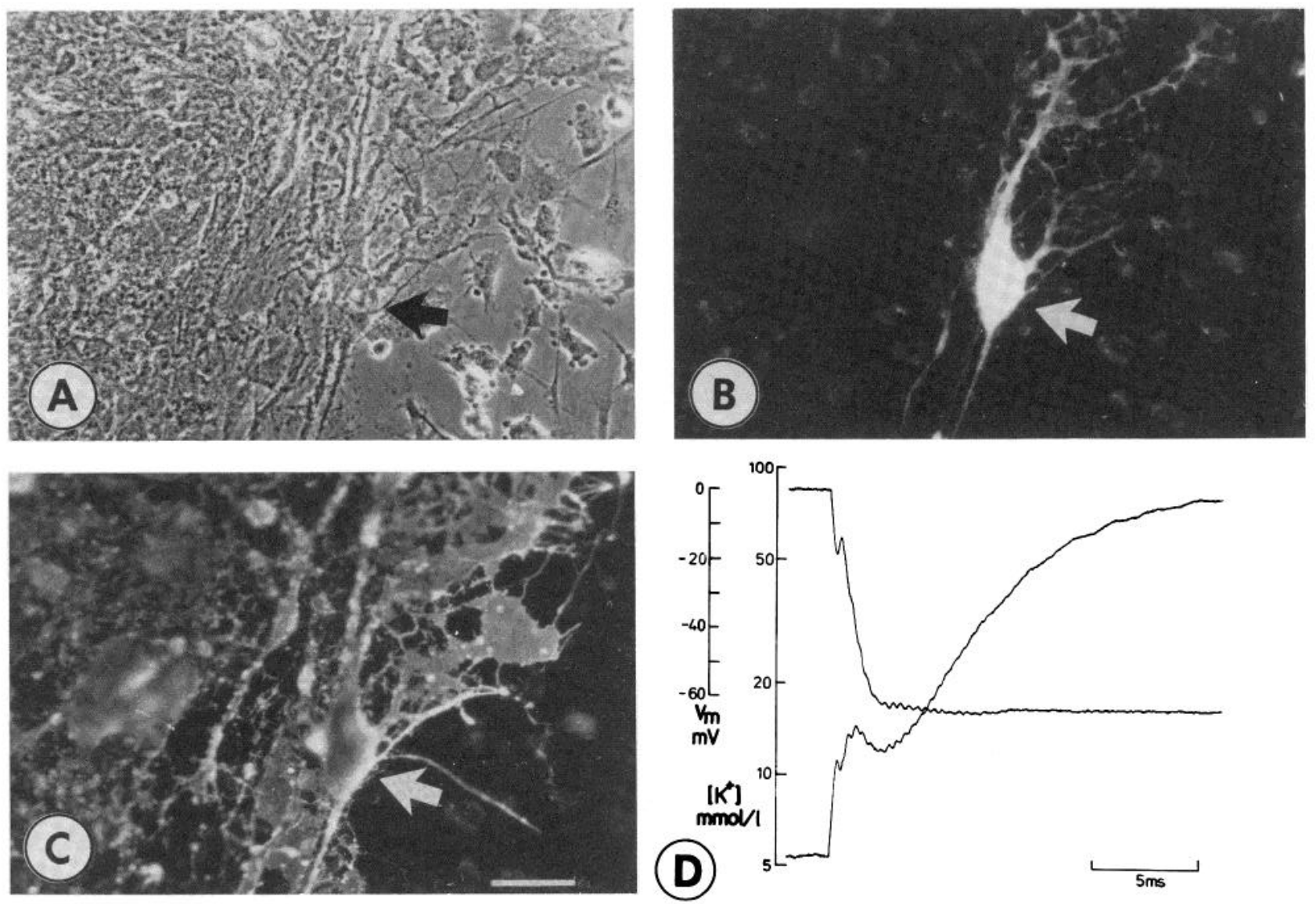

Figure 1. Identification of oligodendrocytes. $A$, Phase contrast picture of an electrophysiologically recorded oligodendrocyte (arrow). B, Lucifer Yellow staining of the recorded cell. $C$, Cell surface staining with the oligodendrocyte-specific antibody 01. $D$, Event of penetration of the same cell as in $A$ to $C$ with a double barreled $\mathrm{K}^{+}$-sensitive microelectrode. $V_{m}$, membrane potential; $\mathrm{K}^{+}$, potassium activity. Note that the rise of the $\mathrm{K}^{+}$-signal is slower than the appearance of the membrane potential due to the larger time constant of the ion-sensitive pipette.

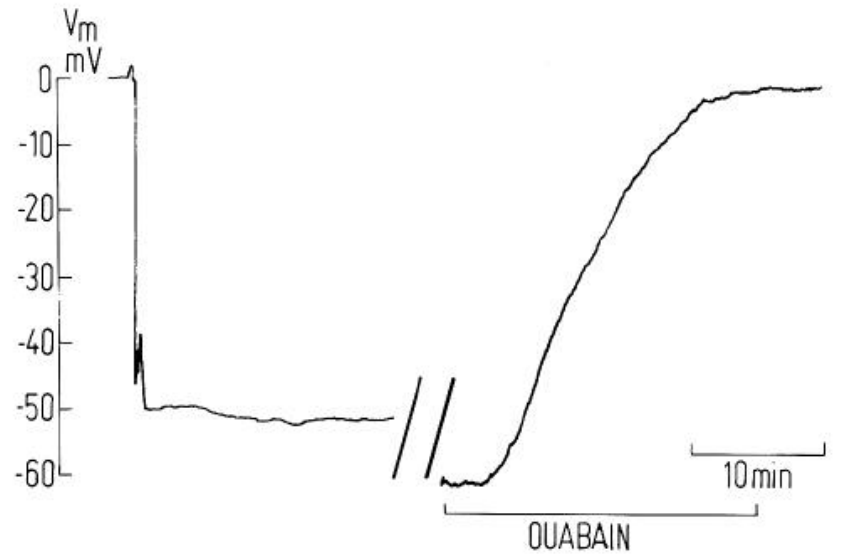

Figure 2. Effect of ouabain on the membrane potential. Ten minutes after the event of penetration, ouabain $\left(10^{-4} \mathrm{~mol} / \mathrm{liter}\right)$ was added to the bathing solution (arrow). Membrane potential $\left(V_{m}\right)$ was reduced to about zero within approximately $10 \mathrm{~min}$.

sion fluid or by pressure ejection of test solutions from a blunt-tipped microelectrode placed above the recorded cell. The exchange of ions was monitored with an appropriate double barreled ion-sensitive electrode in the vicinity of the cell. Slow fluctuations superimposed on the potential recording were about $1 \mathrm{mV}$. Therefore, an influence of varied ion concentrations on the membrane potential of $\leq 1 \mathrm{mV}$ cannot be excluded. For a potential change of $\leq 1 \mathrm{mV}$, we can calculate, based on the Goldmann equation, that the potassium conductance of the membrane is a least 50 times higher than the conductance of sodium, chloride, or calcium ions. Since bath variations of $\mathrm{Cl}^{-}$and $\mathrm{Na}^{+}$were accompanied by transient diffusion potentials which were detected by the potential registration barrel of the extracellular ion-sensitive electrode, microperfusion was preferred because it did not result in diffusion potentials.

Membrane potential and intracellular potassium activity during experimental elevation of extracellular potassium. Potassium in the culture was elevated by exchange of the bath. Measurements with a potassiumsensitive electrode close to the cell showed a $95 \%$ exchange of potassium ions in the superfusing solution within $2 \mathrm{~min}$. The final value of exchanged $\mathrm{K}^{+}$-concentration was reached in 8 to $10 \mathrm{~min}$ (Fig. 4). During the early phase of $\mathrm{K}^{+}$increase, the membrane depolarization closely paralleled the increase of $\left[\mathrm{K}^{+}\right]_{0}$. The slope of the depolarization versus $\left[\mathrm{K}^{+}\right]_{0}$ elevation during the initial rise of $\mathrm{K}^{+}$was about $61 \mathrm{mV}$ for a 10 -fold potassium change. This slope was, however, not maintained con- 
A

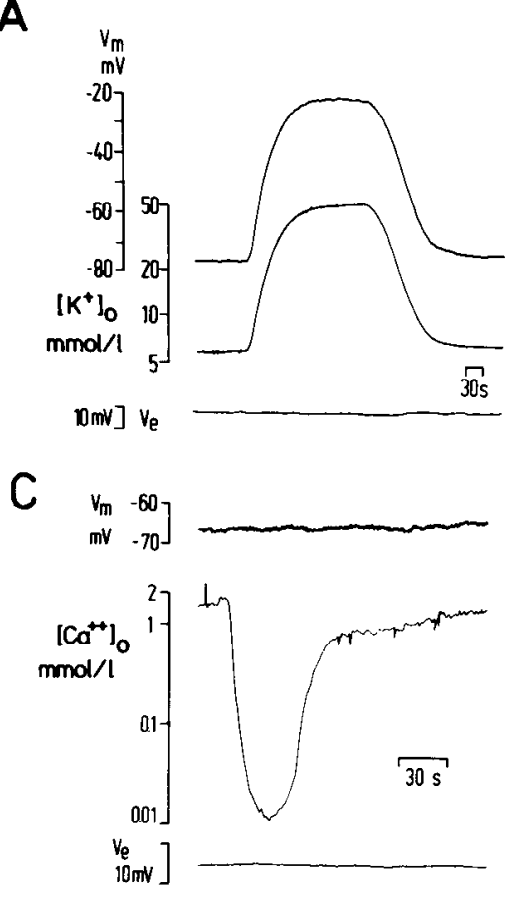

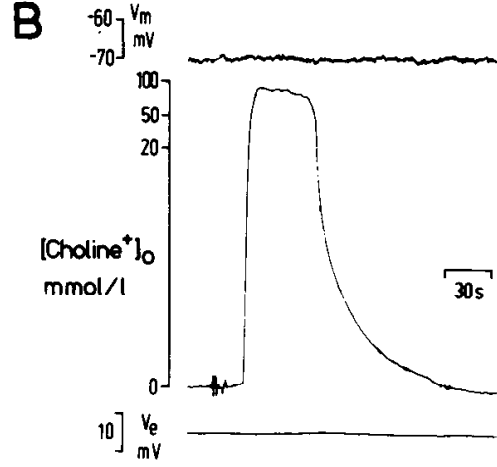

D<smiles>[134Sb]</smiles>

$\left.m_{m} v_{-67}^{-65}\right]$

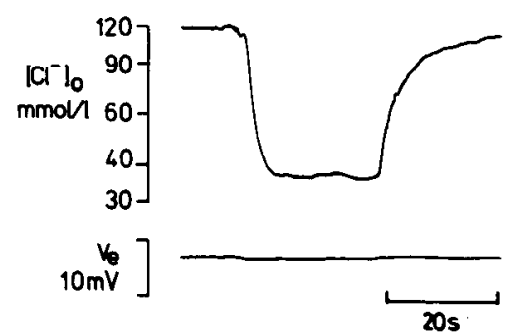

Figure 3. Influence of extracellular ion variations on the membrane potential of oligodendrocytes. $A$, The membrane potential $\left(V_{m}\right)$ is decreased by increased $\left[\mathrm{K}^{+}\right]_{\mathrm{o}} . B$, No influence on the membrane potential by a substitution of sodium against choline (100 $\mathrm{mmol} /$ liter) could be detected. Increase in choline activity was monitored with an electrode filled with Corning ion exchange resin (no. 477137) calibrated with choline. $C$, Reduction of $\left[\mathrm{Ca}^{2+}\right]_{0}$ from 1.7 to $0.01 \mathrm{mmol} /$ liter did not affect the membrane potential. $D$, A decrease of [ $\left.\mathrm{Cl}^{-}\right]_{0}$ from 117 to $40 \mathrm{mmol} /$ liter did not influence measurably the membrane potential. The extracellular ionsensitive electrode was positioned within $5 \mu \mathrm{m}$ close to the cell soma of the intracellularly recorded cell. $V_{e}$, registration of the extracellular potential measured by the reference barrel of the ion-sensitive microelectrode.

stant during the period of slow potassium increase. All cells $(N=30)$ monitored were found to exhibit a progressive decrease in the expected amount of membrane depolarization as $\left[\mathrm{K}^{+}\right]_{0}$ approached the plateau level. During this period the membrane potential did not decrease in response to an increase in $\left[\mathrm{K}^{+}\right]_{0}$, but tended to repolarize. After replacement of elevated $\left[\mathrm{K}^{+}\right]_{0}$ by normal medium, a hyperpolarization above control level was regularly observed. Measurements of intracellular potassium activity revealed a considerable increase of $\mathrm{K}^{+}$ions inside of oligodendrocytes during extracellular elevation of $\mathrm{K}^{+}$. Even small changes of only $1 \mathrm{~mm}$ in $\left[\mathrm{K}^{+}\right]_{0}$ were found to increase $\left[\mathrm{K}^{+}\right]_{\mathrm{i}}$, indicating that the membrane potentials obeyed the Nernst equation also under these conditions.

The simultaneous measurement of extra- and intracellular potassium allowed the calculation of the actual potassium equilibrium potential $\left(E_{K}\right) . E_{K}$ was displayed by an analog summation of the potential change registrated by the extracellular electrode $\left(x_{1} \cdot V_{1}=R \cdot T / Z \cdot F\right.$. $\left.\ln \left[\mathrm{K}^{+}\right]_{0}\right)$ and that measured by the intracellular electrode $\left(x_{2} \cdot V_{2}=R \cdot T / Z \cdot F \cdot \ln \left[\mathrm{K}^{+}\right]_{0} /\left[\mathrm{K}^{+}\right]_{\mathrm{i}}\right)$. The appropriate correcting factors $x_{1}, x_{2}$ accounted for the deviation of the electrode behavior from the Nernst equation. The equilibrium potential for potassium ions $\left(V_{2}-V_{1}=R \cdot T / Z\right.$. $F \ln \left[\mathrm{K}^{+}\right]_{0} /\left[\mathrm{K}^{+}\right]_{\mathrm{i}}$ ) coincides with the membrane potential, indicating an exclusive determination of the membrane potential by the potassium gradient.
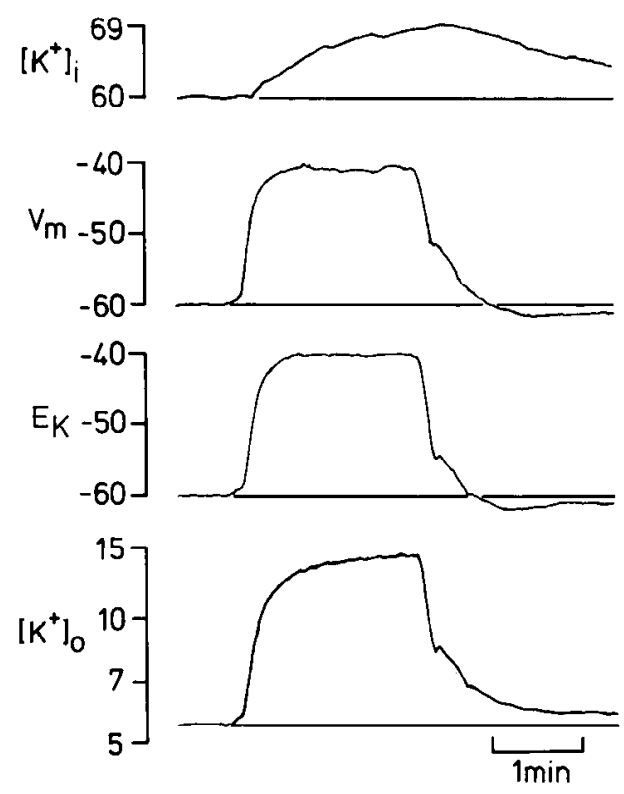

Figure 4. Effect of potassium elevation on membrane potential and internal potassium. Intracellular potassium activity $\left(\left[\mathrm{K}^{+}\right]_{\mathrm{i}}\right)$ and membrane potential $\left(V_{m}\right)$ were registrated during an increase of potassium $\left(\left[\mathrm{K}^{+}\right]_{0}\right)$ in the bathing fluid. The calculated equilibrium potential $\left(E_{K}\right)$ based on the measurement of $\left[\mathrm{K}^{+}\right]_{0}$ and $\left[\mathrm{K}^{+}\right]_{i}$ coincides with $V_{m}$. This indicates an exclusive dependence of $V_{m}$ on the potassium gradient. 


\section{Discussion}

In this paper we describe some basic electrophysiological properties of immunologically identified oligodendrocytes in mouse spinal cord cultures. The use of an oligodendrocyte-specific marker allowed the unequivocal distinction from other glial cell types present in the culture system. This distinction has so far not been attempted in situ by previous investigators.

Ion-sensitive recordings of both intra- and extracellular $\mathrm{K}^{+}$revealed that the membrane potential of mammalian oligodendrocytes is exclusively determined by the potassium gradient as described by the Nernst equation. It is, therefore, not necessary to explain deviations from the Nernst potential by other mechanisms described in the literature which are made under the assumption that intracellular $\mathrm{K}^{+}$-activities remain constant during elevations of extracellular $\mathrm{K}^{+}$concentration. Interfering effects of "spatial buffering" constitute one of those mechanisms and can be excluded because alterations in $\left[\mathrm{K}^{+}\right]_{0}$ were homogeneous over the entire oligodendrocyte cell surface during bath perfusion. Contributions of $\mathrm{Na}^{+}$conductance to the membrane potential as assumed by Ransom and Goldring (1973) do not appear significant, inasmuch as a close correspondence of membrane potential and $E_{K}$ has been observed and because variations of extracellular $\mathrm{Na}^{+}$concentrations did not influence the membrane potential. An increase in $\left[\mathrm{K}^{+}\right]_{\mathrm{i}}$ during elevated extracellular potassium was also found by Coles and Tsacopoulos (1981) in glial cells of the drone retina.

Determinations of intracellular $\mathrm{K}^{+}$activities with ionselective microelectrodes have to be evaluated carefully because the ion exchange resin used in the present study has a cross-sensitivity to sodium ions of 1:200. If intracellular sodium activities are changed during the event of penetration by approximately one decade, as has been observed by Bührle and Sonnhof (1981) in unidentified glial cells in the frog spinal cord, the contribution of $\mathrm{Na}^{+}$ to the determination of $\mathrm{K}^{+}$is less than 1 mmol/liter, which is in the range of spontaneous recording fluctuations. We consider it unlikely that other ions, such as $\mathrm{Ca}^{++}$and $\mathrm{Cl}^{-}$, interfere significantly with the potassium measurement. It is, however, known that polyatomic substances like choline react with the Corning exchange resin, and there are no data available on the content of these substances inside of cultured oligodendrocytes. An overestimation of the intracellular $\mathrm{K}^{+}$activity caused by unknown substances in glial cells of the frog spinal cord, as shown by Bührle and Sonnhof (1981), is also unlikely because membrane potential and $\mathrm{K}^{+}$equilibrium potential $\left(E_{K}\right)$ are in close correspondence. For sodium conductance an additional estimation can be derived from the values of membrane and $\mathrm{K}^{+}$equilibrium potential which differed less than $5 \mathrm{mV}$. Calculations based on the Goldman equation (Goldman, 1943) result in a $\mathrm{Na}^{+}$conductance which is 200 times smaller than that of $\mathrm{K}^{+}$ Therefore, we assume that $\mathrm{K}^{+}$determination is not significantly influenced by $\mathrm{Na}^{+}$.

It is possible that the $\mathrm{K}^{+}$values determined by the electrode placed in the cell soma may differ during transient changes of $\left[\mathrm{K}^{+}\right]_{0}$ from the potassium activity close to the membrane. Diffusion barriers, which could result in a $\mathrm{K}^{+}$concentration gradient within the cells, would then affect the measurement of transient potassium changes. We do not know the depth of insertion of the electrode tip nor the intracellular diffusion constant for potassium ions. However, light and electron microscopic observations show a high surface to volume ratio of oligodendrocytes (Sommer and Schachner, 1981; Berg and Schachner, 1981, 1982), allowing for a fast equilibration of intracellular potassium gradients. Additionally, the excellent agreement between $V_{m}$ and $E_{K}$ during transient changes suggests that these factors are of little importance.

At present, the mechanisms which lead to the intracellular potassium accumulation are not known. Spatial buffering is not involved in the observed intracellular $\mathrm{K}^{+}$ increase in these experiments because extracellular potassium is homogenously distributed in the culture dish during superfusion experiments. In cultured astrocytes, a ouabain-sensitive as well as ouabain-resistant net uptake of potassium was demonstrated by Walz and Hertz (1982). The accumulation of potassium in glial cells may be substantially greater than documented by our activity measurements assuming a swelling of the cells during potassium uptake as proposed by several investigators, e.g., Nicholson (1980). In situ the described potassium uptake mechanisms can effectively contribute to the regulation of $\left[\mathrm{K}^{+}\right]_{0}$, especially under the consideration that the glial volume in brain is larger than that of the extracellular space (Dietzel et al., 1980). At present, it is unclear whether this intracellular potassium accumulation results from passive ion fluxes or active transport. It is a matter for further investigations to analyze this effect, which represents most likely an important factor for the potassium homeostasis in the extracellular space. It will also be important to investigate whether astrocytes and Schwann cells display similar electrophysiological properties as oligodendrocytes in vitro and in situ.

\section{References}

Berg, G., and M. Schachner (1981) Immunoelectronmicroscopic identification of $\mathrm{O}$ antigen bearing oligodendroglial cells in vitro. Cell Tissue Res. 219: 313-325.

Berg, G., and M. Schachner (1982) Immunoelectronmicroscopic characterizqtion of galactocerebroside and nervous system antigen-1 (NS-1) positive oligodendrocytes in culture. Neurosci. Lett. 28: 75-80.

Bührle, C. P., and U. Sonnhof (1981) Intracellular activities of $\mathrm{K}^{+}, \mathrm{Na}^{+}, \mathrm{Ca}^{++}$and $\mathrm{Cl}^{-}$in motoneurons and glial cells of the frog spinal cord. Pflügers Arch. 389 (Suppl.): R24.

Coles, J. A., and M. Tsacopoulos (1981) Ionic and possible metabolic interactions between sensory neurones and glial cells in the retina of the honeybee drone. J. Exp. Biol. 95: 7592.

Dietzel, I., V. Heinemann, G. Hofmeier, and H. D. Lux (1980) Transient changes in the size of the extracellular space in the sensorimotor cortex of cats in reaction to stimulus-induced changes in potassium concentration. Exp. Brain Res. 40: 432439.

Futamachi, K. J., and T. A. Pedley (1976) Glial cells and extracellular potassium: Their relationship in mammalian cortex. Brain Res. 109: 311-322.

Goldman, D. E. (1943) Potential, impedance and rectification in membranes. J. Gen. Physiol. 27: 37-60.

Kuffler, S. W., J. G. Nicholls, and R. K. Orkand (1966) Physiological properties of glial cells in the central nervous system of amphibia. J. Neurophysiol. 29: 768-787. 
Lothman, F. W., and G. G. Somjen (1975) Fxtracellular potassium activity, intracellular and extracellular potential responses in the spinal cord. J. Physiol. 252: 115-136.

Moonen, G., and P. G. Nelson (1978) Some physiological properties of astrocytes in primary cultures. In Dynamic Properties of Glial Cells, E. Schoffeniels, G. Frank, L. Hertz, and D. B. Tower, eds., pp. 389-393, Pergamon Press, London.

Nicholson, C. (1980) Dynamics of the brain cell microenvironment. Neurusci. Res. Program Bull. 18.

Orkand, R. K. (1977) Glial cells. In Cellular Biology of Neurons, E. R. Kandel, ed., vol. I, sect. I, pp. 855-875, Williams \& Wilkins, Baltimore.

Picker, S., S. F. Pieper, and S. Goldring (1981) Glial membrane potentials and their relationship to $\left[\mathrm{K}^{+}\right]_{0}$ in man and guinea pig. J. Neurosurg. 55: 347-363.

Ransom, B., and S. Goldring (1973) Ionic determinants of membrane potential of cells presumed to be glia in cerebral cortex of cat. J. Neurophysiol. 36: 855-868.

Schachner, M., S. K. Kim, and R. Zehnle (1981) Developmental expression in central and peripheral nervous system of oligodendrocyte cell surface antigens ( $O$ antigens) recognized by monoclonal antibodies. Dev. Biol. 83: 328-338.

Schnitzer, J., and M. Schachner (1981) Expression of Thy-1, H2 , and NS- 4 cell surface antigens and tetanus toxin receptors in early postnatal and adult mouse cerebellum. J. Neuroim- munol. 1: 429-456.

Somjen, G. G. (1975) Electrophysiology of neuroglia. Annu. Rev. Physiol. 37: 163-190.

Somjen, G. G. (1979) Extracellular potassium in the mammalian central nervous system. Annu. Rev. Physiol. 41: 159-177.

Sommer, I., and M. Schachner (1981) Monoclonal antibodies (01 to 04) to oligodendrocyte cell surfaces: An immunocytological study in the central nervous system. Dev. Biol. 83: 311-327.

Sommer, I., and M. Schachner (1982) Cells that are 04 antigenpositive and 01 antigen-negative differentiate into 01 antigenpositive oligodendrocytes. Neurosci. Lett. 29: 183-188.

Sonnhof, U., and C. P. Bührle (1980) On the postsynaptic action of glutamate in frog spinal motorneurons. Pflügers Arch. 368: 101-109.

Sonnhof, U., Foerderer, W. Schneider, and H. Kettenmann (1982) Cell puncturing with a step motor driven manipulator with simultaneous measurement of displacement. Pflügers Arch. 392: 295-300.

Stewart, W. (1981) Lucifer dyes-highly fluorescent dyes for biological tracing. Nature 292: 17-21.

Walz, W., and L. Hertz (1982) Ouabain-sensitive and ouabainresistant net uptake of potassium into astrocytes and neurons in primary cultures. J. Neurochem. 39: 70-77. 